\title{
Molecular and Physiological Analysis of the Powdery Mildew Antagonist Pseudozyma flocculosa and Related Fungi
}

\author{
T. J. Avis, S. J. Caron, T. Boekhout, R. C. Hamelin, and R. R. Bélanger
}

First, second, and fifth authors: Département de Phytologie, Université Laval, Québec (Qc), Canada, G1K 7P4; third author: Centraalbureau voor Schimmelcultures, Yeast Division, Julianalaan 67, 2628 BC Delft, the Netherlands; and fourth author: Natural Resources Canada, Centre de Foresterie des Laurentides, 1055 rue du PEPS, P.O. Box 3800, Sainte-Foy (Qc), Canada.

Accepted for publication 20 November 2000.

\begin{abstract}
Avis, T. J., Caron, S. J., Boekhout, T., Hamelin, R. C., and Bélanger, R. R. 2001. Molecular and physiological analysis of the powdery mildew antagonist Pseudozyma flocculosa and related fungi. Phytopathology 91:249-254.

A number of phenotypic and genotypic characteristics were used to ascertain the identity and diversity of Pseudozyma flocculosa, a natural antagonist of powdery mildews that has received little attention in terms of taxonomy. To this end, several putative isolates of $P$. flocculosa as well

identified two previously unknown Pseudozyma isolates as $P$. flocculosa. Random amplified microsatellites revealed three distinct $P$. flocculosa strains among the tested isolates. Biocontrol properties and antifungal metabolite production were limited to the $P$. flocculosa spp. Results produced useful molecular markers to (i) distinguish $P$. flocculosa from other related fungi, (ii) identify different strains within this species, and (iii) aid in the construction of isolate-specific molecular tools that will assist in research and development of $P$. flocculosa as a biocontrol agent of powdery mildew fungi.
\end{abstract} as several closely related species were analyzed. Ribosomal DNA sequences distinguished P. flocculosa from other Pseudozyma spp. and
Additional keywords: antifungal fatty acids
Pseudozyma flocculosa (Traquair, L. A. Shaw \& Jarvis) Boekhout \& Traquair (syn.: Sporothrix flocculosa Traquair, L. A. Shaw \& Jarvis) (6) is a yeastlike fungus with strong antagonistic activity against powdery mildew fungi $(3,11,12,16)$. Cytochemical observations revealed that the antagonist induces rapid collapse of powdery mildew conidial chains and cytoplasmic disintegration of fungal cells (13). The biocontrol agent produces extracellular fatty acids with antifungal properties $(4,7)$. Bioassay of these fatty acids confirmed that they induce the same toxic effect in fungal cells as $P$. flocculosa itself $(1,14)$, confirming their importance in the biocontrol potential of the antagonist.

Current development of this fungus as a biocontrol agent highlights the importance of assessing the identity and diversity of $P$. flocculosa isolates. First and foremost, taxonomic confusions hamper basic research and development of the fungal antagonist as a biocontrol agent. The fungus was initially classified in the genus Sporothrix (20), though recent studies have suggested that it is more closely related to the genus Pseudozyma (2,5). Assessing identity and diversity is also of great importance in the selection of suitable biocontrol candidates as well as in authentication of $P$. flocculosa isolates for industrial procedures and registration purposes (9). Indeed, the efficacy of different isolates may vary with changes in crops and geographic regions of intended use. This may require the re-evaluation of the most effective isolates of the fungus as these conditions evolve in agronomic practices (17). Furthermore, authentication of fungal isolates is critical for consistent results in efficacy in research and commercial trials as well as in the process of mass production in an industrial setting $(19,23)$. In all of these processes, it is essential to have means for the discrimination of $P$. flocculosa from other closely related organisms and to assess variability within the $P$. flocculosa spp. In

Corresponding author: R. Bélanger; E-mail address: richard.belanger@plg.ulaval.ca.

Publication no. P-2000-1222-01R

(c) 2001 The American Phytopathological Society this context, DNA fingerprinting offers a sensitive and reliable approach to genetically characterize the biocontrol agent.

Our objectives were, therefore, (i) to assess ribosomal DNA (rDNA) sequences and random amplified microsatellite (RAMS) fingerprints as tools in identity/diversity studies of $P$. flocculosa and related fungi, and (ii) to correlate this information with biological activity in an attempt to provide a basis of selection of proper candidates for biocontrol programs.

\section{MATERIALS AND METHODS}

Biological materials. Fungal isolates listed in Table 1 were derived from single-spore cultures and were maintained on slants of potato dextrose agar (PDA) at $4^{\circ} \mathrm{C}$. Cells were cultured in potato dextrose broth $(\mathrm{PDB})$ on a rotary shaker $(150 \mathrm{rpm})$ at $25^{\circ} \mathrm{C}$. The fungal biomass was centrifuged at $10,000 \mathrm{rpm}$ for $20 \mathrm{~min}$, and the culture medium was discarded. Fungal cells were washed with sterile distilled water and centrifuged for an additional $20 \mathrm{~min}$. The water was discarded, and the fungal biomass was transferred to sterile $1.5-\mathrm{ml}$ microtubes. The cells were lyophilized and stored at $-20^{\circ} \mathrm{C}$ until use.

DNA extraction. Genomic DNA was prepared as follows. Lyophilized fungi $(\approx 10 \mathrm{mg})$ were mixed with an equal amount of diatomaceous earth (Sigma Chemical Co., St. Louis) and ground with a pestle. Six hundred microliters of extraction buffer (100 mM Tris- $\mathrm{HCl}$ at $\mathrm{pH} 9.5,2 \%$ cetyltrimethylammonium bromide, $1.4 \mathrm{M} \mathrm{NaCl}, 1 \%$ polyethylene glycol $8000,20 \mathrm{mM}$ EDTA, and $1 \% \beta$-mercaptoethanol) was added to the macerated cells and incubated at $65^{\circ} \mathrm{C}$ for $1 \mathrm{~h}$. The mixture was extracted with $600 \mu \mathrm{l}$ of phenol/chloroform/isoamyl alcohol (25:24:1) and centrifuged at $10,000 \times g$ for $5 \mathrm{~min}$. The supernatant was transferred to a new microtube and re-extracted with $400 \mu \mathrm{l}$ of phenol/chloroform/isoamyl alcohol. The supernatant was precipitated with 1 vol of cold isopropanol and centrifuged at $10,000 \times g$ for 5 min. The precipitate was washed with $70 \%$ ethanol, vacuumdried, and resuspended in $50 \mu \mathrm{l}$ of Tris-EDTA buffer (10 mM Tris- 
$\mathrm{HCl}$ and $1 \mathrm{mM}$ EDTA, pH 8). All DNA was diluted (1:100) to a dilution determined to yield the most reproducible polymerase chain reaction (PCR) amplification.

PCR amplification conditions. Three regions of rDNA were amplified (Table 2): the entire region containing both internal transcribed spacers (ITS), partial sequences of the large mitochondrial subunit (mtLSU), and partial sequences of the small nuclear subunit (nSSU). PCR reactions were carried out by the Taq DNA polymerase system (Boehringer Mannheim Biochemica, Mannheim, Germany) in volumes of $25 \mu$ l containing $1 \times$ the supplied reaction buffer (including $1.5 \mathrm{mM} \mathrm{MgCl}_{2}$ ), $100 \mu \mathrm{M}$ each deoxynucleoside triphosphate, $1 \mu \mathrm{M}$ each primer, 1 unit of Taq DNA polymerase, and $1 \mu \mathrm{l}$ of the template DNA. Amplifications were performed in a thermal cycler (MJ Research Inc., Watertown, MA) programmed for an initial denaturation step at $95^{\circ} \mathrm{C}$ for $3 \mathrm{~min}, 35$ cycles at $92^{\circ} \mathrm{C}$ for $30 \mathrm{~s}, 58$ (ITS and mtLSU) or $52^{\circ} \mathrm{C}$ (nSSU) for $30 \mathrm{~s}$, and $72^{\circ} \mathrm{C}$ for $1 \mathrm{~min}$. The amplifications were completed with a 10 -min final extension at $72^{\circ} \mathrm{C}$.

RAMS fingerprints were produced by single-primer amplification with GT and CCA primers (Table 2). PCR was carried out (Expand Long Template PCR; Boehringer Mannheim Biochemica) in $25-\mu \mathrm{l}$ volumes containing $1 \times$ the supplied buffer (including $1.5 \mathrm{mM} \mathrm{MgCl}_{2}$ ), $100 \mu \mathrm{M}$ each deoxynucleoside triphosphate, $0.4 \mu \mathrm{M}$ primer, $2 \%$ dimethyl sulfoxide, 1 unit of Taq Expand DNA polymerase, and $1 \mu \mathrm{l}$ of the template DNA. The thermal cycler was programmed for an initial denaturation step at $95^{\circ} \mathrm{C}$ for $10 \mathrm{~min}, 34$ cycles at $94^{\circ} \mathrm{C}$ for $30 \mathrm{~s}, 58^{\circ} \mathrm{C}$ for $1 \mathrm{~min}$, and $68^{\circ} \mathrm{C}$ for $2 \mathrm{~min}$. The amplifications were completed with an 8 -min final extension at $68^{\circ} \mathrm{C}$. Amplicons were visualized on $1.5 \%$ agarose gels in Tris-acetate-EDTA buffer at $3 \mathrm{~V} / \mathrm{cm}$ for $1.5 \mathrm{~h}$. Gels were stained with ethidium bromide and photographed under UV light.

Nucleotide sequencing determination. rDNA PCR products (ITS, partial mtLSU, and partial nSSU) were purified on minispin columns (QIAquick; Qiagen, Hilden, Germany) and directly sequenced using an aflatoxin biosynthesis inhibitor automated sequencer (373A Strech; Applied Biosystems, Mississauga, Ontario, Canada). Multiple sequence alignment was performed with Clustal W, available on-line from the Baylor College of Medicine. Following visual inspection, final alignment of the sequences was performed by hand. Nucleotide sequences are available in the GenBank database as Accession Nos. AF294690 to AF294724.

Phylogenetic analysis. Phylogenetic analyses were performed by phylogenetic analysis using parsimony (PAUP 4.0b1; Sinauer Associates, Sunderland, MA) on rDNA sequences of the entire ITS region, partial mtLSU, and partial nSSU, both as individual and combined data sets. Indels were coded as single events. Unweighted parsimony analyses were performed on the individual data sets, excluding uninformative characters, using the heuristic search option with 1,000 random addition sequences with MULTREES on and tree bisection-reconnection branch swapping. Maximum parsimony analysis of the combined data set was by the branch-and-bound option in PAUP for exact solutions. The nSSU data set was comprised of a 14-taxon matrix, including sequences from Sporothrix schenckii (GenBank Accession No. M85053). The combined rDNA data set was comprised of an 11-taxon matrix, from which the three Sporothrix spp. were excluded. Saccharomyces sp. (GenBank Accession No. AB040998) and Tilletiopsis washingtonensis were selected as outgroups for rooting the nSSU and combined rDNA trees, respectively. Clade stability was assessed by 1,000 parsimony bootstrap replications. Neighborjoining trees were also inferred with uncorrected "P" and maximumlikelihood distance methods. Concordance of the three rDNA data sets was evaluated with the partition-homogeneity test implemented with PAUP, using 1,000 random repartitions. The KishinoHasegawa likelihood test implemented in PAUP was used to compare various constrained and unconstrained topologies (Table 3).

Production of antifungal fatty acids. Isolates were tested for the production of 9-heptadecenoic and 6-methyl-9-heptadecenoic acids, two antifungal fatty acids produced by $P$. flocculosa (1). Fungi were cultured in PDB for 3 days on a rotary shaker $(150 \mathrm{rpm})$ at $25^{\circ} \mathrm{C}$, followed by a 28 -day still culture, protected from light. Culture media was separated from fungal biomass by centrifugation at $10,000 \mathrm{rpm}$ for $20 \mathrm{~min}$. Culture media was extracted $(3 \times 50 \mathrm{ml})$ with chloroform $(4)$. The combined organic phases were roto-evaporated and taken to dryness with a stream of nitrogen. The oily residue, containing both antifungal fatty acids, was derived with Phenacyl-8 (Pierce Chemical Company, Rockford, IL) (8). Phenacyl ester fatty acids were analyzed by reverse-phase high pressure liquid chromatography (Nova-Pak C-18 column, $60 \AA, 4 \mu \mathrm{m}, 3.9 \times 300 \mathrm{~mm}$ ) coupled to a photodiode array detector (Waters Limited, Mississauga, Ontario, Canada). The eluent was a gradient of 80 to $100 \%$ acetonitile, acidified with $0.1 \% \mathrm{H}_{3} \mathrm{PO}_{4}$, at a $1.0 \mathrm{ml} / \mathrm{min}$ flow rate, as follows: 80 to $100 \%$ over $15 \mathrm{~min}, 100 \%$

TABLE 2. Polymerase chain reaction-amplified regions and primers

\begin{tabular}{|c|c|c|c|}
\hline Genomic region $^{\mathrm{a}}$ & Primer & Sequence ${ }^{b}$ & Ref. $^{c}$ \\
\hline \multicolumn{4}{|l|}{ rDNA } \\
\hline Entire ITS & $\begin{array}{l}\text { ITS1f } \\
\text { ITS } 4\end{array}$ & $\begin{array}{l}\text { 5'-CTTGGTCATTTAGAGGAAGTAA-3' } \\
5^{\prime} \text {-TCCTCCGCTTATTGATATGC-3' }\end{array}$ & $\begin{array}{l}(10) \\
(22)\end{array}$ \\
\hline Partial mtLSU & $\begin{array}{l}\text { ML5 } \\
\text { ML6 }\end{array}$ & 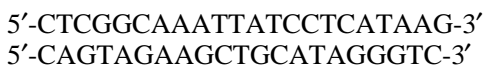 & $\begin{array}{l}(22) \\
(22)\end{array}$ \\
\hline Partial nSSU & $\begin{array}{l}\text { NS51 } \\
\text { NS61 }\end{array}$ & 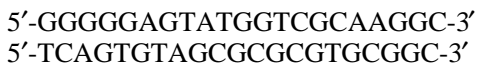 & $\begin{array}{l}\text { TS } \\
\text { TS }\end{array}$ \\
\hline \multicolumn{4}{|l|}{ RAMS } \\
\hline GT repeat & GT & 5'-VHVGTGTGTGTGTGTGTG-3' & $(15)$ \\
\hline CCA repeat & CCA & 5'-DDBCCACCACCACCACCA-3' & (15) \\
\hline
\end{tabular}

a ITS = internal transcribed spacer, $\mathrm{mtLSU}=$ mitochondrial large subunit, nSSU = small nuclear subunit, and RAMS = random amplified microsatellites.

b The following designations are used for degenerate sites: V (G, A, or C), H (A, T, or C), D (G, A, or T), and B (G, T, or C).

c $\mathrm{TS}=$ this study.

TABLE 1. Fungal isolates and species used in this study

\begin{tabular}{|c|c|c|c|c|}
\hline Species & Designation & Isolate $^{a}$ & Host of origin & Geographic origin \\
\hline Pseudozyma flocculosa & PF-A22 & CBS 167.88 & Trifolium pratense & Ontario, Canada \\
\hline Pseudozyma flocculosa & PF-1 & This study & Rose & Québec, Canada \\
\hline Pseudozyma flocculosa & PF-RM & ATCC 74320 & Not applicable & Québec, Canada \\
\hline Pseudozyma flocculosa & PF-IS & This study & Not applicable & Québec, Canada \\
\hline Pseudozyma sp. & $\mathrm{PH}$ & This study & Unknown & Netherlands \\
\hline Pseudozyma sp. & $\mathrm{PBC}$ & This study & Cucumis sativus & British Columbia, Canada \\
\hline Pseudozyma rugulosa & PR & CBS 170.88 & Zea mays & Ontario, Canada \\
\hline Pseudozyma antartica & PAN & CBS 516.83 & Sediment & Antarctica \\
\hline Pseudozyma aphidis & PAP & CBS 517.83 & Aphid secretion & Germany \\
\hline Pseudozyma prolifica & PP & CBS 319.87 & Scirpus microcarpus & Canada \\
\hline Sporothrix inflata & SI & ATCC 24422 & Soil & Germany \\
\hline Sporothrix nivea & $\mathrm{SN}$ & ATCC 76232 & Wastewater & Saskatchewan, Canada \\
\hline Tilletiopsis washingtonensis & TW & ATCC 96156 & Cucumis sativus & British Columbia, Canada \\
\hline
\end{tabular}

a $\mathrm{CBS}=$ Centraalbureau voor Schimmelcultures; ATTC = American Type Culture Collection. 
Analysis of both antifungal fatty acids revealed that PF-A22, PF-1, PF-RM, PF-IS, PBC, and PH produced 9-heptadecenoic acid (Fig. 2). 6-Methyl-9-heptadecenoic acid was produced by PFA22, PF-1, PF-RM, PF-IS, and PBC. PH did not produce 6-methyl-9-heptadecenoic acid. None of the other tested fungi produced either of the antifungal fatty acids.

When selected fungi were bioassayed against Sphaerotheca fuliginea, only the four $P$. flocculosa isolates, $\mathrm{PBC}$, and $\mathrm{PH}$ in- duced collapse of Sphaerotheca fuliginea conidial chains (Fig. 2). The remaining fungi showed no evidence of biocontrol activity against Sphaerotheca fuliginea under our experimental conditions.

\section{DISCUSSION}

P. flocculosa is a recently characterized yeastlike fungus with the potential for biological control of powdery mildew disease.

\begin{tabular}{|c|}
\hline Combined rDNA dataset \\
654 steps \\
$\mathrm{CI}=0.976$ \\
$\mathrm{RI}=0.984$ \\
$\mathrm{RC}=0.960$ \\
\hline
\end{tabular}

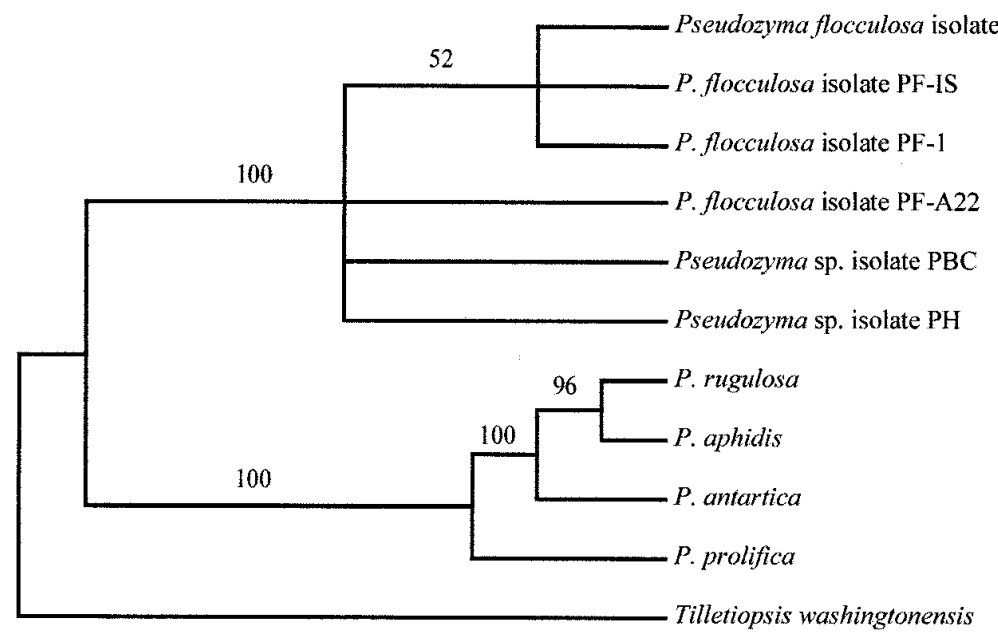

\section{GT CCA}

$\begin{array}{ccc}\text { Production of } & \text { Production of Collapse of } \\ \text { 9-heptadecenoic } & \begin{array}{c}\text { 6-methyl-9- } \\ \text { acid }\end{array} & \text { S. fulliginea } \\ \text { heptadecenoic } & \text { conidia } \\ \text { acid } & \end{array}$

$\begin{array}{ccccc}\text { la } & 1 a & \text { Yes } & \text { Yes } & \text { Yes } \\ 1 \mathrm{a} & 1 \mathrm{a} & \text { Yes } & \text { Yes } & \text { Yes } \\ 1 \mathrm{a} & 1 \mathrm{a} & \text { Yes } & \text { Yes } & \text { Yes } \\ 1 \mathrm{a} & 1 \mathrm{a} & \text { Yes } & \text { Yes } & \text { Yes } \\ 1 \mathrm{~b} & 1 \mathrm{~b} & \text { Yes } & \text { Yes } & \text { Yes } \\ 1 \mathrm{~b} & 1 \mathrm{c} & \text { Yes } & \text { No } & \text { Yes } \\ 2 & 2 \mathrm{a} & \text { No } & \text { No } & \text { No } \\ 3 & 2 b & \text { No } & \text { No } & \text { No } \\ 4 & 3 & \text { No } & \text { No } & \text { No } \\ 5 & 4 & \text { No } & \text { No } & \text { No } \\ 6 & 5 & \text { No } & \text { No } & \text { No }\end{array}$

Fig. 2. Strict consensus of the five most parsimonious trees based on the combined data set of three rDNA sequences. Bootstrap replication frequencies $>50 \%$ are indicated above nodes. GT = GT-primed microsatellite fingerprint; and CCA = CCA-primed microsatellite fingerprint.

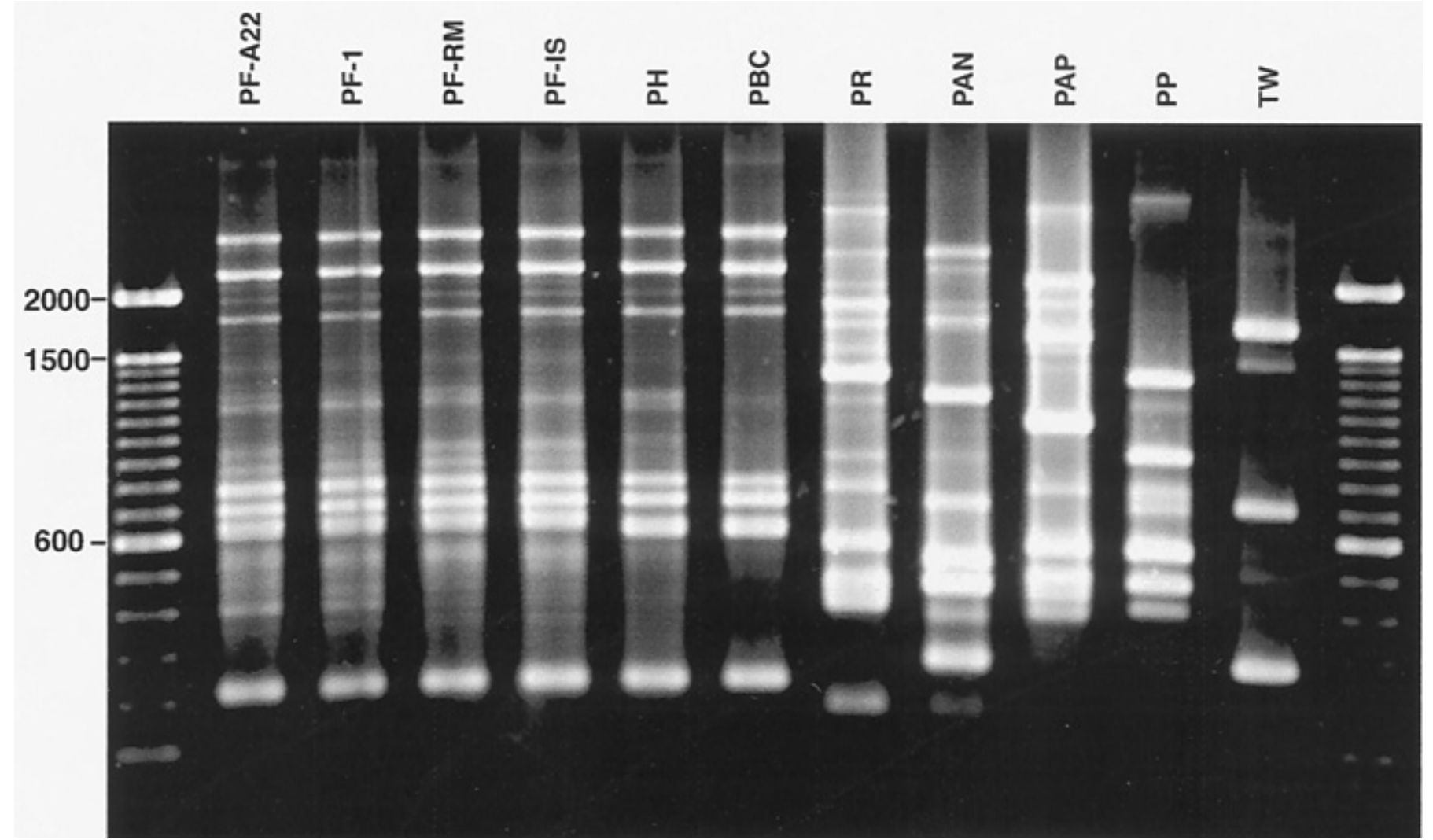

Fig. 3. Random amplified microsatellite fingerprints generated by GT primer. Designation of isolates is given in Table 1 . Lanes 1 and 13 are molecular size markers (100-bp ladder). 
When selecting fungi for a specific purpose or function it is essential to correctly classify and identify isolates for the selection of appropriate candidates in given situations. This precise identification is also necessary to ensure consistency in experimental, industrial, and commercial processes. In this study, a mixture of phenotypic and genotypic characteristics were studied to ascertain the identity and diversity of the known $P$. flocculosa isolates in order to gain insight into the strains that are of interest in biocontrol programs.

P. flocculosa was initially classified in the genus Sporothrix based on classical mycology techniques (20). Recent studies have suggested that the fungus is in fact from the genus Pseudozyma, based, in part, on sequences of the large nuclear subunit (nLSU) of rDNA $(2,5)$. In this work, the nSSU of rDNA was used to directly compare Pseudozyma isolates, including $P$. flocculosa, with three Sporothrix spp. These results conclusively demonstrate that $P$. flocculosa is indeed distant from Sporothrix spp. and is more closely related to the genus Pseudozyma.

Cladistic analysis of the combined data set of three rDNA sequences clearly demonstrated that the tested Pseudozyma fungi are distributed into five distinct species based on their high bootstrap values ( $95 \%$ or greater). This is consistent with previous reports that have used the nLSU of rDNA $(2,5)$. Moreover, the Kishino-Hasegawa likelihood test forcing the monophyly of the unknown Pseudozyma isolates from British Columbia (PBC) and the Netherlands (PH) with the four P. flocculosa isolates indicated that both PBC and PH should be considered as part of the $P$. flocculosa species.

Microsatellite fingerprinting of $P$. flocculosa isolates suggested that the four isolates from Ontario and Québec are very closely related. These results were expected because these four isolates were initially derived from a single strain. Also, microsatellite fingerprints of $\mathrm{PBC}$ and $\mathrm{PH}$ indicated that they are both distinct strains of $P$. flocculosa. Previous results with random amplified polymorphic DNA analysis also revealed that $\mathrm{PH}$ was distinct from PBC and PF-A22, although this analysis could not distinguish the latter two isolates between each other (21).

Under the test conditions used in this study, biocontrol activity against Sphaerotheca fuliginea, causal agent of cucumber powdery mildew, was limited to the six P. flocculosa isolates, including $\mathrm{PH}$ and $\mathrm{PBC}$, indicating that biocontrol properties are not a general characteristic of Pseudozyma spp. but are specific to certain species. Although P. rugulosa has been reported to antagonize Sphaerotheca fuliginea (11), this was not demonstrated in our experiments.

Two of the antifungal fatty acids that mediate the biocontrol properties of $P$. flocculosa were produced in all P. flocculosa isolates, with the exception of $\mathrm{PH}$, which only produces 9-heptadecenoic acid. This may play an important role in the selection of the most prolific $P$. flocculosa isolate in biocontrol programs. $P$. rugulosa produces a related antifungal fatty acid, 4-methyl-7,11heptadecadienoic acid, but did not produce either of the two antifungal fatty acids tested in this study. This may well affect the general biocontrol property of $P$. rugulosa, which is less effective than $P$. flocculosa in controlling powdery mildew (11).

Overall, this study indicates that $P$. flocculosa can be genetically and biochemically discriminated from other related fungi. Current results demonstrated that there are three distinguishable $P$. flocculosa strains capable of biocontrol activity against Sphaerotheca fuliginea. Although this biocontrol fungus has a very limited genetic base, i.e., there are few known isolates, these findings provide a basis to identify, authenticate, and monitor these isolates, and possibly others yet to be discovered. This is of paramount importance in the production and release of $P$. flocculosa in a biocontrol program. For example, as experimental and commercialscale testing of these isolates against other powdery mildew fungi as well as in different cultural and geographical conditions continues, these molecular markers will be useful in the selection of the most effective isolates in a given situation. Moreover, should more than one isolate of P. flocculosa be mass-produced in an industrial setting, these molecular markers would be instrumental in the detection of cross contamination between isolates in a quality control test (18). These findings could permit the construction of molecular tools based on isolate-specific sequences. This may allow the possible detection of mutations that could, if followed by selection or genetic drift, alter the genetic integrity and, potentially, the biocontrol property of the fungus. The discovery of specific and useful genetic markers in this study will, thus, be instrumental in gaining insight into the reliable use of a $P$. flocculosa-based biological fungicide against powdery mildew diseases.

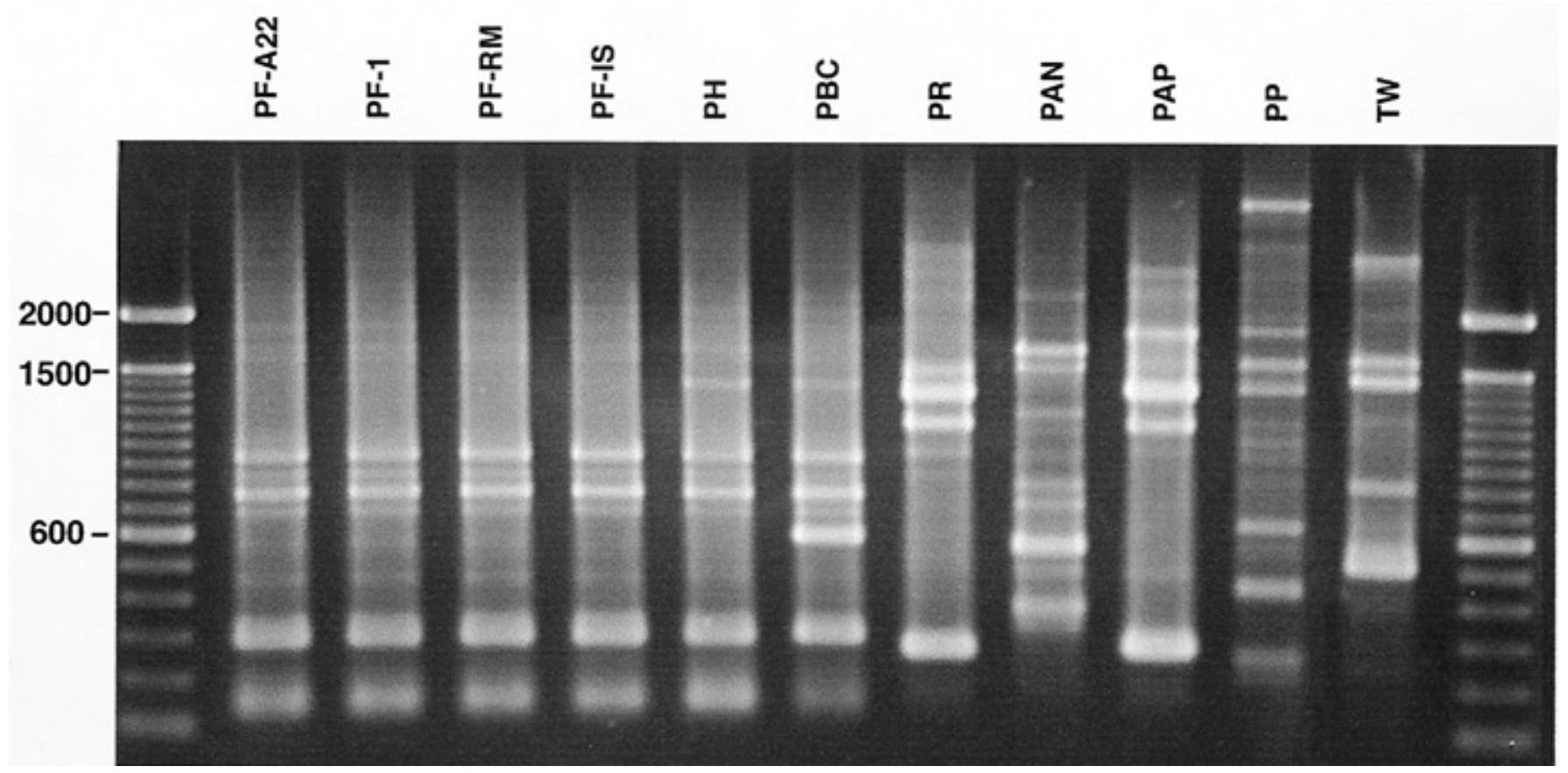

Fig. 4. Random amplified microsatellite fingerprints generated by CCA primer. Designation of isolates is given in Table 1 . Lanes 1 and 13 are molecular size markers (100-bp ladder). 


\section{ACKNOWLEDGMENTS}

This work was supported by a grant from the Natural Sciences and Engineering Research Council of Canada and Plant Products Co. Ltd. We thank D. Auclair, H. Germain, and N. Lecours for technical assistance, and K. O’Donnell for assistance with phylogenetic analysis.

\section{LITERATURE CITED}

1. Avis, T. J., and Bélanger, R. R. 2000. Synthesis and biological characterization of (Z)-9-heptadecenoic and (Z)-6-methyl-9-heptadecenoic acids, fatty acids with antibiotic activity produced by Pseudozyma flocculosa. J. Chem. Ecol. 26:987-1000.

2. Begerow, D., Bauer, R., and Boekhout, T. 2000. Phylogenetic placements of ustilaginomycetous anamorphs as deduced from nuclear LSU rDNA sequences. Mycol. Res. 104:53-60.

3. Bélanger, R. R., Labbé, C., and Jarvis, W. R. 1994. Commercial-scale control of rose powdery mildew with a fungal antagonist. Plant Dis. 78:420-424.

4. Benyagoub, M., Bel Rhlid, R., and Bélanger, R. R. 1996. Purification and characterization of new fatty acids with antibiotic activity produced by Sporothrix flocculosa. J. Chem. Ecol. 22:405-413.

5. Boekhout, T. 1995. Pseudozyma Bandoni emend. Boekhout, a genus for yeast-like anamorphs of Ustilaginales. J. Gen. Appl. Microbiol. 41:359-366.

6. Boekhout, T., Fell, J. K., and O'Donnell, K. 1995. Molecular systematics of some yeast-like anamorphs belonging to the ustilaginales and tilletiales. Stud. Mycol. 38:175-183.

7. Choudhury, S. R., Traquair, J. A., and Jarvis, W. R. 1994. 4-Methyl-7,11heptadecadenal and 4-methyl-7,11-heptadecadienoic acid: New antibiotics from Sporothrix flocculosa and Sporothrix rugulosa. J. Nat. Prod. 57:700-704.

8. Durst, H. D., Milano, M., Kikta, E. J., Jr., Connelly, S. A., and Grushka, E. 1975. Phenacyl esters of fatty acids via crown ether catalysts for enhanced ultraviolet detection in liquid chromatography. Anal. Chem. 47:1797-1801.

9. Fravel, D. R., Rhodes, D. J., and Larkin, R. P. 1999. Production and commercialization of biocontrol agents. Pages 365-376 in: Integrated Pest and Disease Management in Greenhouse Crops. R. Albajes, M. Lodovica Guillino, J. C. van Lenteren, and Y. Elad, eds. Kluwer Academic Publishers, Dordrecht, the Netherlands.

10. Gardes, M., and Burns, T. D. 1993. ITS primers with enhanced specificity for basidiomycetes-application to the identification of mycorrhizae and rusts. Mol. Ecol. 2:113-118.

11. Hajlaoui, M. R., and Bélanger, R. R. 1991. Comparative effects of temperature and humidity on the activity of three potential antagonists of rose powdery mildew. Neth. J. Plant Pathol. 97:203-208.

12. Hajlaoui, M. R., and Bélanger, R. R. 1993. Antagonism of the yeast-like phylloplane fungus Sporothrix flocculosa against Erysiphe graminis var. tritici. Biocontrol Sci. Technol. 3:427-434.

13. Hajlaoui, M. R., Benhamou, N., and Bélanger, R. R. 1992. Cytochemical study of the antagonistic activity of Sporothrix flocculosa on rose powdery mildew, Sphaerotheca pannosa var. rosae. Phytopathology 82:583-589.

14. Hajlaoui, M. R., Traquair, J. A., Jarvis, W. R., and Bélanger, R. R. 1994. Antifungal activity of extracellular metabolites produced by Sporothrix flocculosa. Biocontrol Sci. Technol. 4:229-237.

15. Hantula, J., Dusabenyagasani, M., and Hamelin, R. C. 1996. Random amplified microsatellites (RAMS): A novel method for characterizing genetic variation within fungi. Eur. J. Plant Pathol. 26:159-166.

16. Jarvis, W. R., Shaw, L. A., and Traquair, J. A. 1989. Factors affecting antagonism of cucumber powdery mildew by Stephanoascus flocculosus and S. rugulosus. Mycol. Res. 92:162-165.

17. Kiss, L., and Nakasone, K. K. 1998. Ribosomal DNA internal transcribed spacer sequences do not support the species status of Ampelomyces quisqualis, a hyperparasite of powdery mildew fungi. Curr. Genet. 33:362-367.

18. Markovic, O., and Markovic, N. 1998. Cell cross-contamination in cell cultures: The silent and neglected danger. In Vitro Cell. Dev. Biol. 34:1-8.

19. Stacey, G. N., Bolton, B. J., and Doyle, A. 1991. The quality control of cell banks using DNA fingerprinting. Pages 361-370 in: DNA Fingerprinting: Approaches and Applications. T. Burke, G. Dolf, A. J. Jeffreys, and R. Wolff, eds. Birkhauser Verlag, Basel, Switzerland.

20. Traquair, J. A., Shaw, L. A., and Jarvis, W. R. 1988 New species of Stephanoascus with Sporothrix anamorphs. Can. J. Bot. 66:926-933.

21. Urquhart, E. J., Sun, L. J., and Punja, Z. K. 1997. Identification of species of Tilletiopsis using random amplified polymorphic DNA analysis. Can. J. Plant Pathol. 19:380-389.

22. White, T. J., Burns, T., Lee, S., and Taylor, J. 1990. Amplification and direct sequencing of fungal ribosomal RNA genes for phylogenetics. Pages 315-322 in: PCR Protocols: A Guide to Methods and Applications. M. A. Innis, D. H. Gelfand, J. J. Sninsky, and T. J. White, eds. Academic Press, New York.

23. Woodhead, S. H., O'Leary, A. L., O'Leary, D. J., and Rabatin, S. L. 1990. Discovery, development, and registration of a biocontrol agent from an industrial perspective. Can. J. Plant Pathol. 12:328-331. 